\title{
Buffer storage for direct steam generation
}

\author{
Wolf-Dieter Steinmann *, Markus Eck \\ German Aerospace Center (DLR), Institute of Technical Thermodynamic, Pfaffenwaldring 38-40, D-70569 Stuttgart, Germany
}

Received 13 October 2004; received in revised form 29 April 2005; accepted 11 May 2005

Available online 14 July 2005

\begin{abstract}
Fast reaction times and high discharge rates make steam accumulators a promising option for compensation of fast transients in insolation for solarthermal systems using steam as working medium. Using the volume of components like separator drums or heat exchangers for storage of pressurized hot water is a cost-effective approach to integrate buffer storage capacity. While the basic steam accumulator shows a decline in pressure during the discharge process, there are also concepts maintaining constant pressure. The integration of latent heat storage material allows an increase in volumetric storage capacity. The availability of steam accumulators for compensation of fast transients also helps to reduce the requirements concerning reaction time and discharge rate for storage systems intended for supplying stored energy over longer periods.
\end{abstract}

(c) 2005 Elsevier Ltd. All rights reserved.

Keywords: Solar power; Energy storage; Steam accumulator; Ruths; Direct steam generation; Solarthermal power plants; Steam cycle

\section{Introduction}

The availability of cost effective storage systems plays an important role for an increased market penetration of solarthermal power plants. Different concepts for integrated thermal storage units are currently under development for parabolic trough systems. These concepts can be classified according to the storage capacity. The aim of buffer storage systems is the compensation of fast transients in solar insolation which are usually not predictable. Characteristic requirements for these buffer storage systems are short reaction times and high discharge rates while the thermal capacity is usually in the range of 5-10 min. Buffer storage systems are

\footnotetext{
${ }^{*}$ Corresponding author. Tel.: +497116862785 ; fax: +49711 6862747.

E-mail address: wolf.steinmann@dlr.de (W.-D. Steinmann).
}

intended to protect the components of the power plant from the effects of high thermal transients resulting from sudden variation in solar insolation. The integration of buffer storage capacity simplifies the control of the power plant and allows an extended reaction time for backup systems, which are intended to compensate longer periods of reduced insolation. Steam accumulators are especially suited to meet the requirements for buffer storage in solar steam systems, providing saturated steam at pressures up to $100 \mathrm{bar}$. The introduction of steam accumulators in solarthermal power plants can profit from practical experience gained in operating similar storage systems in fossil fired facilities over decades. These storage systems are used in process industry to balance demand and generation of steam. In the Berlin island grid, a power plant with $50 \mathrm{MW}$ electric power was operated with steam accumulators of $67 \mathrm{MW}$ h storage capacity over a period of more than 60 years (Beckmann and Gilli, 1984). 


\section{Nomenclature}

\section{$A, B, C$ constants for the Antoine equation}

$c_{\text {liquid }} \quad$ specific heat capacity of liquid phase

$h^{\prime} \quad$ specific enthalpy saturated liquid

$h^{\prime \prime} \quad$ specific enthalpy saturated steam

$h_{\text {exit }} \quad$ specific enthalpy of steam at exit of pressure vessel

$\Delta h_{\text {evaporate }}$ heat of vaporization

$\Delta h_{\text {evaporate, m }}$ average heat of vaporization for discharge process

$\Delta h_{\text {evaporate, ref }}$ reference value heat of vaporization for Watson equation

$\begin{array}{ll}m_{\text {liquid }} & \begin{array}{l}\text { mass of liquid phase in vessel } \\ m_{\text {Steam }}\end{array} \\ \begin{array}{l}\text { mass of saturated steam provided during } \\ \text { discharge process }\end{array} \\ m_{\text {Vessel }} & \begin{array}{l}\text { mass of water in pressure vessel } \\ \text { pressure at begin of discharge process }\end{array} \\ p_{\text {start }} & \text { pressure at end of discharge process } \\ p_{\text {end }} & \text { pressure in vessel } \\ p_{\text {Vessel }} & \text { saturation temperature } \\ t_{\text {sat }} & \text { internal energy of water in pressure vessel } \\ u_{\text {Vessel }}\end{array}$

$m_{\text {liquid }} \quad$ mass of liquid phase in vessel discharge process

$m_{\text {Vessel }}$ mass of water in pressure vessel

$p_{\text {start }}$

$p_{\text {end }}$

$u_{\text {Vessel }}$

\section{Basic concept of steam accumulators}

The direct storage of saturated or superheated steam in pressure vessels is not economic due to the low volumetric energy density. Instead, steam accumulators use sensible heat storage in pressurized saturated liquid water (Goldstern, 1970). They profit from the high volumetric storage capacity of liquid water for sensible heat due to its high specific heat capacity. Steam is produced by lowering the pressure of the saturated liquid during discharge. Fig. 1 shows the scheme of a steam accumulator. Since water is used both as storage medium and working medium high discharge rates are possible, while the capacity is limited by the volume of the pressure vessel. The volume specific thermal energy density depends strongly on the variation of the saturation temperature resulting from the pressure drop during discharge, characteristic values are in the range of $20-30 \mathrm{~kW} \mathrm{~h} / \mathrm{m}^{3}$. During the charging process either the temperature of the liquid water is increased by condensation of superheated steam or the mass in the volume is increased by feeding saturated liquid water into the system. If superheated steam is used, the pressure in the vessel increases during the charging process while there is only a little variation of the liquid storage mass. If saturated liquid

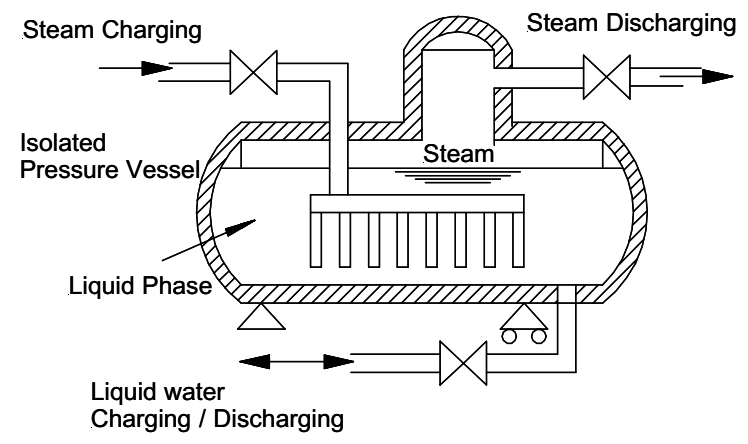

Fig. 1. Scheme of sliding pressure steam accumulator. is fed into the steam accumulator, the pressure remains constant. A steam accumulator can also be charged indirectly; here, a heat exchanger is integrated into the liquid volume. The medium flowing in the heat exchanger need not be water, heat from a source working at lower pressure can be used. In sliding pressure systems (also called Ruths storage systems) saturated steam leaves the storage vessel during the discharge process. Fig. 2 shows the amount of steam produced from $1 \mathrm{~m}^{3}$ of liquid water during a pressure drop of 1 bar dependent on the initial saturation pressure. The range of steam production in Fig. 2 corresponds to a thermal energy between $0.26 \mathrm{~kW} \mathrm{~h} / \mathrm{bar} / \mathrm{m}^{3}$ and $0.19 \mathrm{~kW} \mathrm{~h} / \mathrm{bar} / \mathrm{m}^{3}$. The saturation pressure affects the rate of steam production in different ways: at higher pressures, the pressure dependent change of saturation temperature decreases, so the change in sensible energy in the liquid water volume becomes smaller. The density of saturated liquid water is reduced with pressure resulting in a lower volumetric energy density. On the other side, mass specific energy

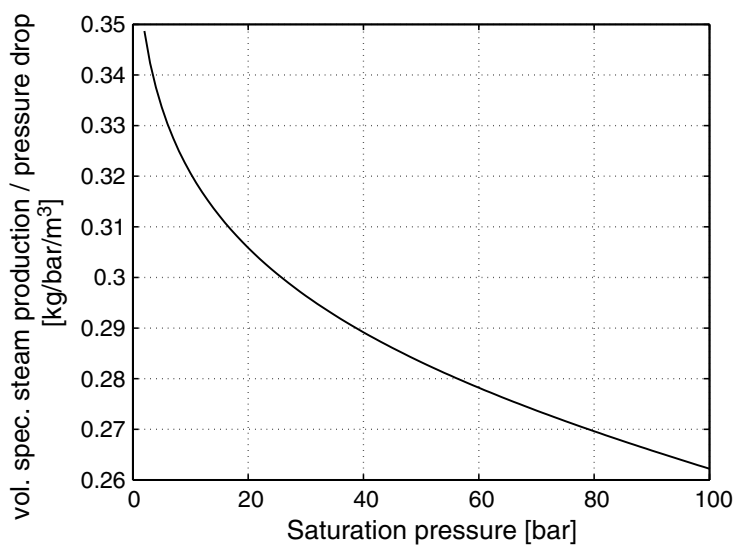

Fig. 2. Mass of produced saturated steam associated with pressure reduction of 1 bar in a steam accumulator dependent on saturation pressure in vessel; mass of produced steam refers to volume of liquid water. 
needed for evaporation is smaller at higher pressures. Fig. 2 shows that for a given pressure drop steam accumulators operated at a lower pressure level provide more saturated steam; if the pressure at the end of the discharge process is fixed, a storage system starting at a higher initial pressure level might provide more steam due to the larger variation of pressure.

\section{Integration of steam accumulators in solarthermal power plants}

The practical feasibility of direct steam generation (DSG) in parabolic trough collectors has been proven in recent years, reaching temperatures of $400{ }^{\circ} \mathrm{C}$ at pressures of up to 100 bar (Eck et al., 2003). The application of steam accumulators for this technology is a straightforward solution for integration of buffer storage capacity in solarthermal power plants using this collector concept. Fig. 3 shows the flow sheet for a DSG power plant with integrated steam accumulator. If the steam production of the collector field exceeds the demand of the turbine, the surplus steam is condensed in the steam accumulator. During periods of reduced insolation, steam is taken from the steam accumulator to support or replace the steam production of the solar field. It is advantageous to operate solar steam systems in the socalled recirculation mode; here, not the complete water that is fed into the collector field is evaporated. Wet steam exits the evaporation section and enters a separator. The gas phase is either fed into a saturated steam turbine or superheated in another section of the collector field, the liquid phase is pumped back to the inlet of the evaporator section of the collector field.

Regarding the integration of steam accumulators, it is a cost effective approach to combine storage and phase separation in a single component. Fig. 4 shows

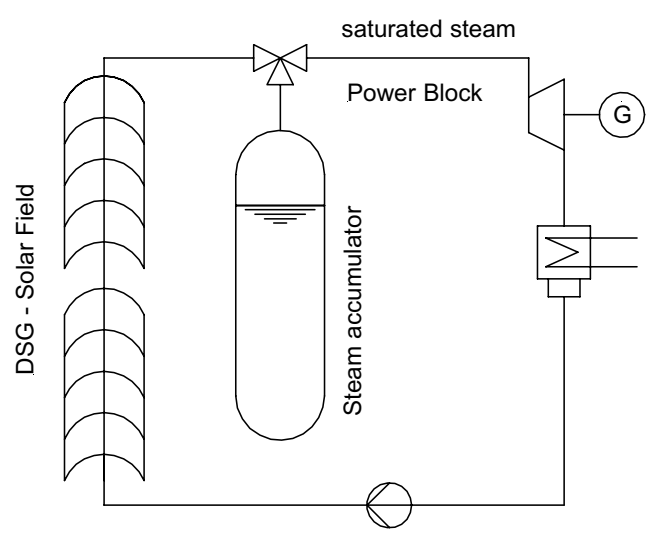

Fig. 3. Simplified scheme of solarthermal power plant with direct steam generation (DSG) in parabolic troughs and integrated steam accumulator. the scheme of a DSG-power plant operated in recirculation mode: wet steam from the evaporation section of the collector field enters the steam accumulator/separator. Here, the phases are separated. During the charging process, the amount of saturated liquid leaving the vessel is smaller than the amount entering the volume through the wet steam feed line. The pressure in the steam accumulator/separator remains constant, no specific charging devices for condensation of steam are necessary inside the volume. The steam accumulator is discharged by lowering the pressure in the volume and extracting steam. This concept demands almost no additional hardware, modifications mainly affect the operation strategy of the power plant.

Steam accumulators can also be applied in systems which use thermal oil as heat transfer medium in solar collectors provided steam is produced for electricity generation or as process steam (Fig. 5). Again, combining

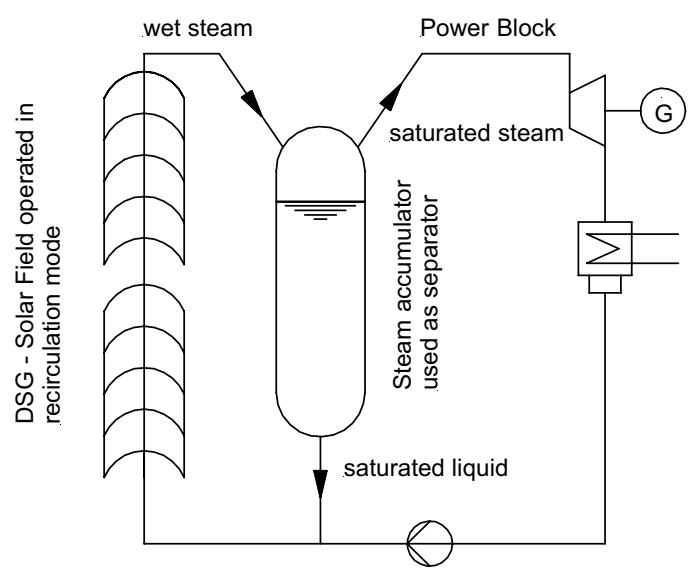

Fig. 4. DSG-power plant with steam accumulator also used as phase separator at the exit of the collector field.

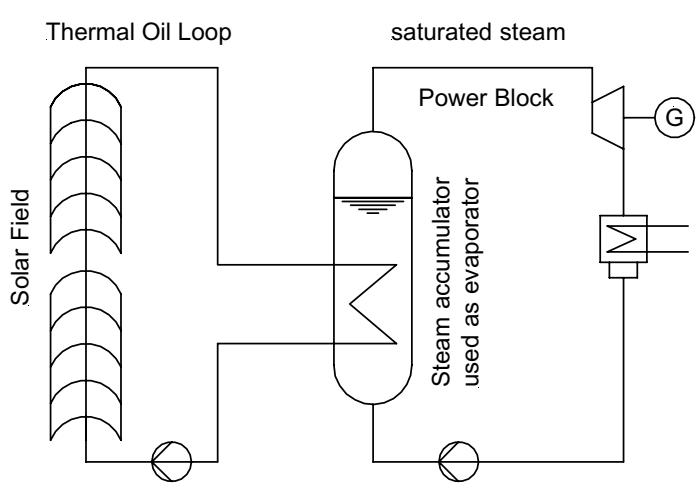

Fig. 5. Parabolic trough power plant using oil as heat transfer medium in collectors; indirect charging of steam accumulator which is also used as heat exchanger. 


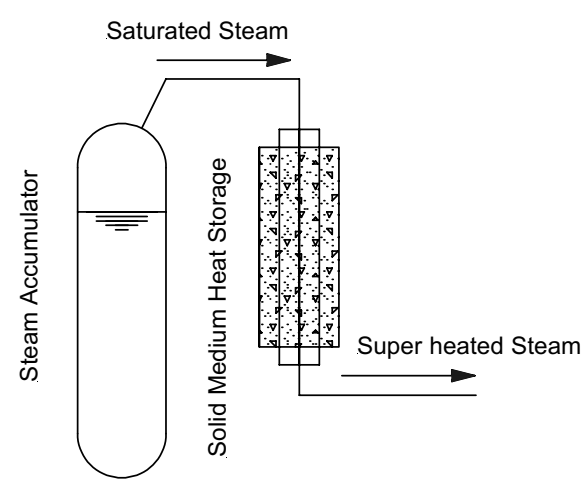

Fig. 6. Combination of steam accumulator with additional sensible storage system to provide superheated steam.

the steam accumulator with an already existing component offers a cost-effective option for introducing buffer storage capacity. This kind of solarthermal systems requires a heat exchanger to transfer thermal energy from the thermal oil to the water/steam loop; the pressurized liquid water volume in this heat exchanger can be used for energy storage. The steam accumulator is charged indirectly by the thermal oil flowing in a tube register located in the liquid volume. By variation of the liquid water level the charge state of the steam accumulator changes.

Steam accumulators provide saturated steam; if superheated steam is needed, a second storage system can be connected to the exit of the steam accumulator. Candidate concepts for this second storage system use either solid storage media like concrete or non-pressurized liquids like molten salt for sensible heat storage. In most solar steam applications, only a small fraction of the thermal energy is needed for superheating. In a solarthermal power plant using parabolic troughs, only $10-15 \%$ of the thermal energy is needed for superheating steam (Tamme et al., 2004), so the contribution of the additional storage system is significantly smaller than the share of the steam accumulator (Fig. 6).

\section{Constant pressure concepts}

In a Ruths-type steam accumulator the steam pressure drops during discharge. For some applications, a storage system providing steam at constant pressure is advantageous. One option to avoid a pressure drop is the application of a separate flash evaporator (Fig. 7): the saturated liquid water taken from the steam accumulator is depressurized externally, cold water is fed into the storage vessel to keep the water level constant, mixing of hot and cold water must be minimized, thermal stress resulting from filling the pressure vessel with cold water must be considered. Another option for constant pressure storage is the

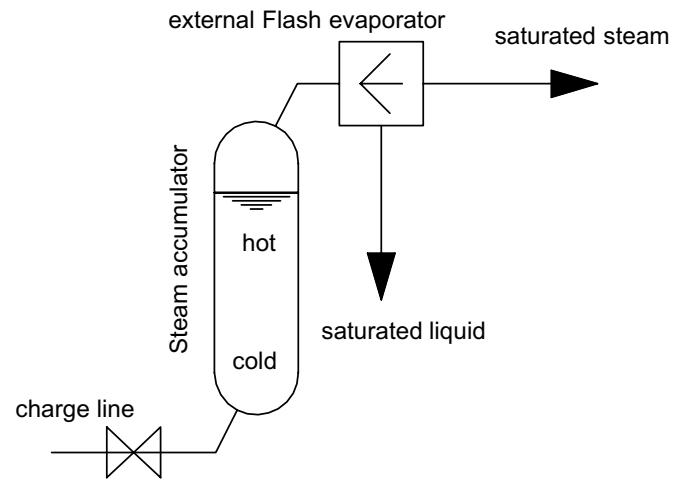

Fig. 7. Constant pressure concept; external depressurization.

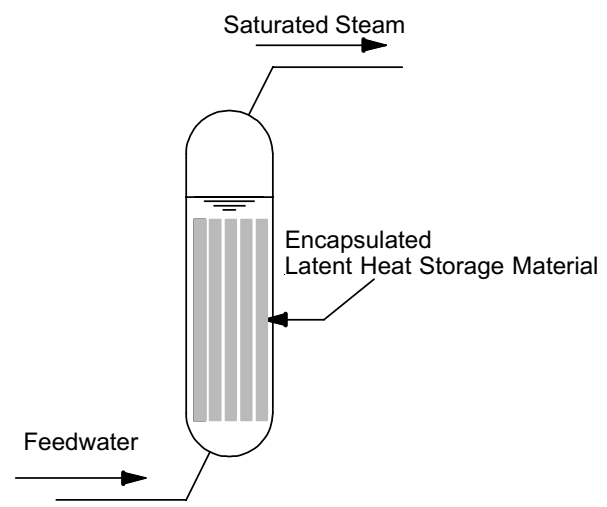

Fig. 8. Steam accumulator with integrated latent heat storage material.

integration of phase change material (PCM) into the storage vessel partly replacing the liquid water (Fig. 8). Here, the thermal energy associated with the phase change between liquid and solid state is used for isothermal energy storage. PCMs usually exhibit a low thermal conductivity so layers of this material must be thin to ensure a sufficient heat transfer rate. One option to fulfill this demand is the encapsulation of PCM in small containers placed inside the liquid volume. Using PCM is not only attractive regarding the avoidance of thermo-mechanical stress resulting from temperature transients, the characteristic volume-specific storage capacity of PCMs is in the range of about $100 \mathrm{~kW} \mathrm{~h} / \mathrm{m}^{3}$. Compared to the corresponding value for water $\left(20-30 \mathrm{~kW} \mathrm{~h} / \mathrm{m}^{3}\right)$, the integration of PCM helps to increase the storage capacity of a given pressure vessel.

\section{Physical model of sliding pressure steam accumulator}

For the physical model it is assumed that there is no heat transfer between the environment and the fluid vol- 
ume inside the pressure vessel or between the walls of the pressure vessel and the fluid volume. The fluid inside the pressure vessel should be always in thermal equilibrium.

During the discharge process, the change in internal energy of the liquid water volume with mass $m_{\text {vessel }}$ in the pressure vessel of the steam accumulator corresponds to the enthalpy flow transported by the exiting mass flow $\mathrm{d} m_{\text {Vessel }}$ :

$\mathrm{d}\left(m_{\text {Vessel }} u_{\text {Vessel }}\right)=h_{\text {exit }} \mathrm{d} m_{\text {Vessel }}$

It is assumed that the specific exit enthalpy $h_{\text {exit }}$ equals the specific enthalpy $h^{\prime \prime}$ of saturated steam at pressure $p_{\text {Vessel }}$ so from (1):

$u_{\text {Vessel }} \mathrm{d} m_{\text {Vessel }}+m_{\text {Vessel }} \mathrm{d} u_{\text {Vessel }}=h^{\prime \prime}\left(p_{\text {Vessel }}\right) \mathrm{d} m_{\text {Vessel }}$

The integration of Eq. (2) provides the mass of saturated steam that is provided during the discharge of the steam accumulator. Fig. 9 shows the amount of saturated steam delivered by the steam accumulator depending on the final pressure at the end of the discharge process for different initial pressures. The dashed lines demonstrate the application of the diagram for the example discussed in Section 6.

The following assumptions allow a quick estimation of the storage capacity for discharge from pressure $p_{\text {start }}$ to $p_{\text {end }}$ for a given liquid volume with mass $m_{\text {liquid: }}$

- complete heat for evaporation is provided by the liquid phase,

- specific heat capacity of liquid water is approximated by average value $c_{\text {liquid,m }}$ for saturated liquid water at average pressure $p_{\mathrm{m}}=\left(p_{\text {start }}+p_{\text {end }}\right) / 2$,

- specific heat of vaporization is approximated by aver-

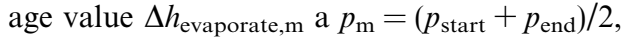

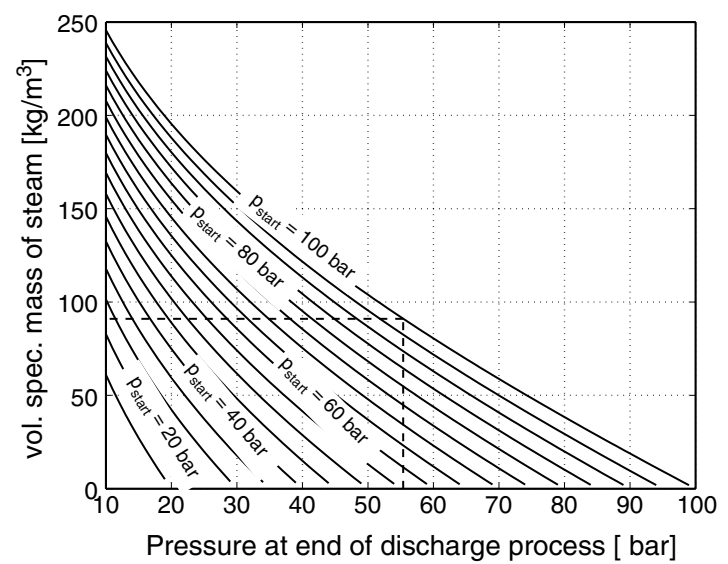

Fig. 9. Volume specific mass of saturated steam provided by steam accumulator for different initial pressures and pressure drops. Dashed line indicates example discussed in Section 6 with initial pressure $=100$ bar and final pressure 55 bar; steam accumulator delivers approx. $90 \mathrm{~kg}$ saturated steam per $\mathrm{m}^{3}$ storage volume.
- the change in liquid mass $m_{\text {liquid }}$ during depressurization is neglected.

With these assumption, the mass of saturated steam $m_{\text {Steam }}$ provided by the steam accumulator is

$m_{\text {Steam }} \Delta h_{\text {evaporate, } \mathrm{m}}=m_{\text {liquid }} c_{\text {liquid, } \mathrm{m}}\left(t_{\text {sat }}\left(p_{\text {start }}\right)-t_{\text {sat }}\left(p_{\text {end }}\right)\right)$

The left side of Eq. (3) represents the enthalpy provided by the steam accumulator during the discharge process while the right side is the change of internal energy of the liquid water inside the pressure vessel.

Two empirical correlations for saturation temperatures $t_{\text {sat }}$ and heat of vaporization $\Delta h_{\text {evaporate }}$ are applied (Reid et al., 1988):

Antoine equation:

$$
\begin{aligned}
& t_{\text {sat }}\left[{ }^{\circ} \mathrm{C}\right]=\frac{B}{A-\ln p_{\text {sat }}[\mathrm{bar}]}-C \\
& A=11.934, \quad B=3985, \quad C=234.1
\end{aligned}
$$

Watson equation:

$\Delta h_{\text {evaporate }}=\Delta h_{\text {evaporate, } \text { ref }}\left(\frac{1-(t+273.15) / 647}{1-\left(t_{\text {ref }}+273.15\right) / 647}\right)^{0.38}$

$\Delta h_{\text {evaporate, ref }}$ is the known heat of vaporization for a selected temperature $t_{\text {ref }}$.

Combination of Eqs. (3)-(5) provides an estimation for the total mass of saturated steam $m_{\text {Steam }}$ provided during the discharge process starting at pressure $p_{\text {start }}$ with final pressure $p_{\text {end }}$ depending on the mass of liquid water $m_{\text {liquid }}$ :

$$
m_{\text {Steam }}=\frac{m_{\text {liquid }} c_{\text {liquid }, \mathrm{m}} B\left(\frac{1}{A-\ln p_{\text {start }}}-\frac{1}{A-\ln p_{\text {end }}}\right)}{\Delta h_{\text {evaporate, ref }}\left(\frac{1-\left(\frac{B}{A-\ln p_{\mathrm{m}}}-C+273.15\right) / 647}{1-\left(t_{\text {ref }}+273.15\right) / 647}\right)^{0.38}}
$$

\section{Steam accumulators for solar direct steam generation}

Fig. 10 shows the DISS test facility for Direct Steam Generation in parabolic troughs. This test facility is operated in a pressure range between 30 and 100 bar and steam outlet temperatures up to $400{ }^{\circ} \mathrm{C}$, the peak thermal power is $2 \mathrm{MW}$ (Eck et al., 2003). A separator drum divides the collector into an evaporation section and a superheating section. By using this pressure vessel for hot water storage the separator can be operated as a steam accumulator. During the charging process, the amount of liquid water leaving the drum is smaller than the mass flow of the liquid phase provided by the solar collector to the separator, the water level in the drum rises. This concept demands no specific devices for steam condensation and allows charging at constant pressure. 


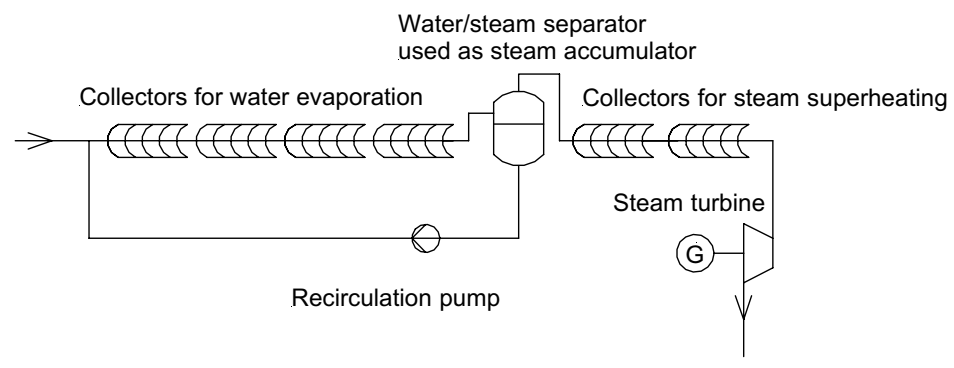

Fig. 10. Scheme of the DISS test loop for direct steam generation in parabolic troughs with separator used as steam accumulator.

Assuming a pressure drop from 100 bar to 55 bar, Fig. 9 provides a volume specific saturated steam production of about $90 \mathrm{~kg} / \mathrm{m}^{3}$ during the discharge. The volume for saturated liquid water of the drum is approx. $4 \mathrm{~m}^{3}$, so about $360 \mathrm{~kg}$ saturated steam can be provided The nominal mass flow rate of the collector is $1.2 \mathrm{~kg} / \mathrm{s}$, so the steam accumulator can replace the collectors for about $5 \mathrm{~min}$.

\section{Conclusion and outlook}

Steam accumulators represent an attractive option for facilitating the operation of solarthermal power plants by offering short time energy storage. The integration of steam accumulators mainly aims at the compensation of fast transients in insolation. Thermo-mechanical stress resulting from fluctuations in solar irradiation can be limited in the components of the power plant by the availability of steam accumulators, the response time of storage systems intended for operation over several hours can be extended if steam accumulators are used in the initial phase of storage operation. This response time affects the investment costs for storage systems, so steam accumulators also help to improve the cost efficiency of long time storage.

The investment costs for steam accumulators are dominated by the pressure vessel, the use of components like steam drums, feedwater tanks or deaerators as storage vessels offers an interesting option for the limitation of additional investment costs for steam accumulator systems. Here, the development of adapted operation strategies is required.

Regarding the pressure vessel of the steam accumulator, the detailed analysis of the thermo-mechanical stress in the storage vessel during charging/discharging will help to optimize the storage systems. An interesting aspect here is also the flow field of gas phase and liquid phase inside the pressure vessel which might be controlled by inserts to limit temperature gradients in the vessel wall.

\section{References}

Beckmann, G., Gilli, P.V., 1984. Thermal Energy Storage. Springer-Verlag, Berlin.

Eck, M., Zarza, E., Eickhoff, M., Rheinländer, J., Valenzuela, L., 2003. Applied research concerning the direct steam generation in parabolic troughs. Solar Energy 74, 341-351.

Goldstern, W., 1970. Steam Storage Installation. Pergamon Press, Oxford.

Reid, R.C., Prausnitz, J.M., Poling, B.E., 1988. The Properties of Gases \& Liquids, fourth ed. McGraw-Hill Book Company.

Tamme, R., Laing, D., Steinmann, W.-D., 2004. Advanced thermal energy storage technology for parabolic trough. ASME J. Solar Energy Eng. 126, 794-800. 